\title{
Vertical Democratic Meritocracy in China: Response to Comments
}

\author{
Daniel A. Bell \\ Professor and Dean of the School of Political Science and Public \\ Administration, Shandong University, China \\ bei@sdu.edu.cn
}

Let me first thank editor Benjamin Hammer for organizing this series of exchanges. My book The China Model: Political Meritocracy and the Limits of Democracy $^{1}$ has generated much heat and light. The first two comments-by Huang Yushun and Liu Jingxi - generate heat and the second two commentsby Zhang Yongle and Cao Feng-generate light. I take special pleasure in the comments that generate light because I can learn from them. But I also need to respond to comments that generate heat because it is important to clarify misunderstandings and to spell out areas of irreconcilable differences. Let me begin by discussing the first two comments, and then I will say what I have learned from the last two comments. ${ }^{2}$ For reasons of space, I cannot respond to all the detailed argumentation, nor will I engage with the polemics.

\section{What's Wrong with Endorsing Both Political Democracy and Political Meritocracy?}

It is important to clarify the relationship between political meritocracy and democracy. Both Huang Yushun and Liu Jingxi argue that democracy should serve as the standard for selecting and promoting leaders, regardless of the level of government and the history and culture of a country. They oppose any form of political meritocracy and propose a one-size-fits-all solution to

1 Daniel Bell, The China Model: Political Meritocracy and the Limits of Democracy (Princeton: Princeton University Press, 2015).

2 The fifth comment - by Fang Zhaohui - is interesting, but I will not respond because it does not involve the topic of political meritocracy or my book on the topic. Let me just say that I agree with Fang's critique of Lucian Pye's work. 
the problem of political rule that has been the subject of intense debate by political theorists since the age of Confucius and Plato. My view is sensitive to context. The ideal that I defend is "vertical democratic meritocracy": democracy at the lower levels of government and political meritocracy at higher levels of government, with political experimentation in between. Democracy refers to the idea of politics by the people, and political meritocracy refers to the idea that the political system should aim to select and promote public officials with above-average ability and virtue. In my view, both democracy and political meritocracy are important, and we need to think about how they can best fit together in particular contexts.

My argument is that the ideal of vertical democratic meritocracy should be used to evaluate the political reality in China, but not necessarily elsewhere. I then apply this principle to the contemporary Chinese context and show that a large gap exists between the ideal and the reality, and propose measures for reducing this gap. But why should "vertical democratic meritocracy" be employed as the standard for evaluating the political system in China? There are four reasons. First, size matters: the ideal applies only in a large country. It is much more difficult to rule and manage huge and incredibly diverse countries such as China, and it is not helpful to compare China to small, relatively homogeneous countries endowed with plentiful natural resources. ${ }^{3}$ Moreover, at higher levels of government of large countries, problems are complex and often affect many sectors of society, the rest of the world, and future generations. In large countries, political success is more likely with leaders who have political experience at lower levels of government and a good performance record. Electoral democracy may be appropriate for small countries or at lower levels of government of large countries; even if things go wrong-say, too much populism or small-minded navel-gazing at the cost of neglecting longterm planning and concern for future generations and the rest of the world-it is not the end of the world. But it may well be the end of the world if things go severely wrong at the top of big and powerful countries. Nobody worries about the fact that Nicaragua has not signed the Paris accord on dealing with climate change, but President Donald Trump's disregard for the accord may well be disastrous for the world. The policies of leaders at the top of huge political

3 Francis Fukuyama argues that Denmark is the country that comes closest to realizing the ideal of liberal democracy (see his book Political Order and Political Decay: From the Industrial Revolution to the Globalization of Democracy [New York: Farrar, Straus and Giroux, 2015]). But it seems absurd to suggest that the political system of a relatively homogeneous, well-off country of 5.7 million people surrounded by small, friendly neighbors be used as the benchmark for assessing political success in large countries, such as the United States, India, or China. 
communities shape the lives of hundreds of millions of people, including future generations and the rest of the world. Hence, the ideal of political meritocracy is more appropriate to assess the higher levels of political systems of large countries, such as China.

Second, the ideal of political meritocracy has a long history in China. More than 2,500 years ago, Confucius defended the view that exemplary people [junzi 君子] have superior ability and virtue (as opposed to the earlier view that junzi have aristocratic family backgrounds), and since then Chinese intellectuals have argued over which abilities and virtues matter for government, how to assess those abilities and virtues, and how to institutionalize a political system that aims to select and promote public officials with superior abilities and virtues. It is no exaggeration to say that the ideal of political meritocracy was taken for granted in most political debates in Chinese history. ${ }^{4}$ And China's two-thousand-year experience with a complex bureaucratic system can be viewed as a constant effort to institutionalize the ideal of political meritocracy. But the ideal does not necessarily apply in political contexts where the ideal of political meritocracy was not so central and that lacked a long history of bureaucracy inspired by meritocratic ideals. Moreover, it is extremely challenging to build up institutions inspired by the ideal of political meritocracy, and it takes decades for such efforts to yield some success (in contrast, it is not so difficult to institutionalize free and fair competitive elections, even in chaotic countries such as Iraq or Afghanistan; whether those elections lead to good results for the political community is a different question).

Third, the ideal of vertical democratic meritocracy has inspired political reform in China over the past four decades or so. A typical trope in the Western media is that substantial economic reform has taken place in China, but no political reform. However, that is because electoral democracy at the top is viewed as the only standard for what counts as political reform. If we set aside this dogma, it becomes obvious that the Chinese political system has undergone substantial political reform over the past few decades, and the main difference is that a serious effort has been made to (re)establish political meritocracy at higher levels of government. The country was primed for rule at the top by meritocratically selected officials following a disastrous experience with radical populism and arbitrary dictatorship during the Cultural Revolution,

4 Huang claims that I distort Confucian thought, but he does not provide any evidence that Confucians supported the idea that people should have equal rights to participate in politics before the encounter with Western political thought in the mid-to late nineteenth century. It is certainly true that Confucians often advocated criticisms of mistaken policies and open discussion of political matters, but that does not translate into a defense of equal rights to political participation or elections as a way of selecting rulers. 
and China's leaders could reestablish elements of its meritocratic tradition, such as the selection of leaders based on examination and promotion based on performance evaluations at lower levels of government-almost the same system, in form (but not content) that shaped the political system for much of Chinese imperial history - without much controversy. Since then, political meritocracy has inspired political reform at higher levels of government, with more emphasis on education, examinations, and political experience at lower levels of government. A large gap remains between the ideal and the practice, but the underlying motivation for political reform is still the ideal of vertical political meritocracy.

Fourth, survey results consistently show widespread support for the ideal of political meritocracy (aka guardianship discourse) in China, especially at higher levels of government. The ideal is widely shared, much more so than the ideal of selecting leaders through elections. And the ideal of political meritocracy is also widely used to evaluate the political system. Corruption became such a big issue in the popular mind at least partly because of the expectation that meritocratically selected leaders should possess superior virtue. But the ideal of political meritocracy may not be an appropriate standard for evaluating political progress (and regress) in societies where the ideal is not widely shared and is not typically used by the people to evaluate their political leaders.

That said, the way in which I framed this issue in my book may have led to misunderstanding. "Vertical democratic meritocracy" is a matter of tendencies, not a matter of absolutes. I may have given the impression that I object to any form of political meritocracy at lower levels of government and to any form of democracy at higher levels of government. But I do not mean to deny the need for some form of political meritocracy at lower levels of government and the need for some form of democracy at higher levels of government, even if the principle should still be "the higher the level of government, the greater the need for meritocratic mechanisms for the selection and promotion of leaders." When I present my book in mainland China, a typical reaction is that more political meritocracy is needed at lower levels of government, not just at higher levels, because local elections are often corrupt. I agree. Here in Shandong Province, for example, Confucian-trained intellectuals inspired by Liang Shuming's example from the pre-revolutionary era provide moral education for farmers in the countryside. Such meritocratic mechanisms that aim to improve the quality of decision-making in villages can and should be welcomed. But they should not replace democratic foundations, and the ultimate aim should be to promote more democracy at the local level, where the people are best placed to understand local needs and to assess the quality of their leaders. 
Along with Huang and Liu, I also agree that more democratic mechanisms are needed at higher levels of government. Unlike, say, fascism or totalitarianism, political meritocracy is compatible with most democratic values and practices. Non-electoral forms of political participation, such as consultation and deliberative polling, as well as freedom of speech, are theoretically compatible with political meritocracy at the top. But political meritocracy is not compatible with competitive elections at the highest level of government because electoral democracy for top leaders would wreck the advantages of a system that aims to select and promote leaders with experience, ability, and virtue: an elected leader without any political experience (e.g., Donald Trump) could rise to the top (and make many beginner's mistakes), an elected leader would have to spend valuable time raising funds and giving the same speech over and over again, instead of thinking about policy, and an elected leader would be more constrained by short-term electoral considerations at the expense of long-term planning for the good of the political community and the rest of the world.

So what are the differences between my views and those of Huang and Liu? The differences are political, not philosophical. They oppose any form of political meritocracy and favor democracy at all levels of government, including electoral democracy at higher levels of government. And they defend this principle as a universal value that should serve as the standard for evaluating political progress and regress, regardless of a country's historical context, national characteristics, or size. My view is different. I wholeheartedly endorse some universal values: as noted in my book, widespread agreement exists on the value of basic human rights and prohibitions against slavery, genocide, murder, torture, prolonged arbitrary detention, and systemic racial discrimination, as well as the idea that all citizens should be equal before the law in criminal cases. I also think that, as societies modernize, their need for more democratic mechanisms increases. More freedom of speech and association (short of the right to form political parties that compete for power at higher levels of government) is necessary as societies become more complex and citizens become more educated and demanding. Non-electoral forms of political participation, such as the right to exercise oversight of the government and the right to provide advice, can help to satisfy the desires of the ambitious and public-spirited people outside the political system. Such tendencies characterize other modernizing East Asian societies, including Singapore, which explicitly appeals to meritocracy as a source of legitimacy, and there is no reason to think that China will be an exception. But electoral democracy at the top will eliminate the advantages of "vertical democratic meritocracy," and that is where we need to draw the line. Huang and Liu would probably disagree with 
this caveat, but at a minimum we need to be clear about where we disagree. I am prepared to change my mind, but Huang and Liu would need to explain why they think electoral democracy would be beneficial at the top in a large country with a tradition of political meritocracy that still enjoys wide support among the people. Rather than simply asserting their political preferences, they would need to support their claims with evidence from contemporary social science and history, as well as explain why leaders elected by the people are more likely to deal with global challenges, such as climate change and regulating dangerous forms of artificial intelligence. I look forward to such debates, and I hope that they can be carried out in a civil and respectful manner so that we can learn and improve from our exchanges: both Confucius and John Stuart Mill would surely agree that we should strive to learn from alternative views! I hope to learn from my critics, so let me turn to two comments that provided learning opportunities.

2

\section{Maoism and Daoism: Remedying the Drawbacks of Political Meritocracy}

In chapter 3 in my book, I discuss the drawbacks of political meritocracy and propose ways of remedying those drawbacks short of electoral democracy at the top. The first drawback is that rulers selected on the basis of their superior ability may abuse their power. I argue that China has developed mechanisms to deal with this problem, such as collective leadership and term and age limits. ${ }^{5}$ But these safeguards are not sufficient. To deal with corruption, I argue that Confucian moral education and institutional safeguards are needed. What I did not expect is that the anti-corruption drive could achieve relatively rapid success in the couple of years since my book was published. The main reason for success is that the anti-corruption drive has relied on the Legalist tradition, that is, the use of fear and harsh punishments as a means to maintain social order. But Legalism can only be effective in the short term. For long-term success to be achieved, the public must internalize the notion that corruption is a moral evil, and public officials should abstain from engaging in corruption even when they do not worry about being caught. So I still think Confucian

5 Recent developments in China are not encouraging, but it is worth noting that electoral democracies are also vulnerable to abuses of power: elected politicians in Russia, Turkey, Poland, Hungary, and even the United States scapegoat minorities and violate basic rights. There is no single institutional safeguard that can rein in politicians hungry for power, especially if they enjoy widespread support in society at large. 
moral education, with its emphasis on moral transformation, has an important role. It is encouraging that Confucian moral education has been revised in the formal education system and in schools for training public officials. But success in transforming attitudes will take years, and such measures must also be accompanied by measures that reduce the incentives for engaging in corruption, including higher salaries for public officials and clearer separation of economic and political power.

The second drawback to political meritocracy is that it can lead to the ossification of political hierarchies. This has been a recurring problem throughout Chinese history, with a constant need for new thinking about meritocratic ideas and institutions designed to break down ossified hierarchies and to ensure equality of opportunity among members of the political community. ${ }^{6}$ In contemporary China, perhaps the biggest problem is the large gap between rich and poor, which means that those born to wealthier families have a greater likelihood of eventually attaining political power. Hence, it is imperative to reduce the gap between rich and poor, but this, too, will take years to achieve.

The third drawback is the problem of legitimacy: in a political meritocracy without competitive elections at the top that give all citizens the hope (or illusion) that they can participate in the political system, it is difficult to legitimize that system to those outside it. In my book, I argue that the current sources of legitimacy —nationalism, performance, and meritocracy—will not be sufficient in the future and that the problem of legitimacy can be addressed only through democratic reforms. I propose the idea of a referendum on "vertical democratic meritocracy" that would be an explicit form of popular consent. I defend the idea of a referendum on the grounds that the electorate tends to be unusually well-informed when they vote in referenda on major constitutional issues compared to regular democratic elections. My views were influenced by my own experience with two referenda on the question of Quebec's independence. Since I wrote the book, however, Brexit has shaken my faith in referenda. If the electorate in the world's most mature democracy can vote in a less-thanrational ways - the levels of education and actual interaction with European migrants in the UK inversely correlated with votes in favor of Brexit-why should we expect more sensible voters in a relatively poor country without a long history of democracy? So if a referendum on vertical democratic meritocracy is held in China, perhaps it should be accompanied by meritocratic checks, such as a simple multiple-choice test on political options designed by independent experts.

6 See Wang Pei, "Debates on Political Meritocracy in China: A Historical Perspective," Philosophy and Public Issues 7, no. 1 (2017). 
But this proposal for a referendum may seem far-fetched in the Chinese context. Meanwhile other mechanisms are needed to secure more democratic legitimacy for the political system, especially to secure the endorsement of those outside it. And here the comments by Zhang and Cao are particularly helpful. Zhang argues that Confucian education emphasized virtue "in order to maintain a sense among the people that the career of a political requires special talents and training, and perhaps only suits a minority of people." However, it is also necessary to affirm the idea that "the average person can also participate in public affairs at the grassroots level, and even realize outstanding achievements and achieve recognition by the state." China's revolution, inspired by Mao's thought, allowed for the possibility that average people could achieve recognition by the state. For one thing, a less intellectual view of what constitutes political merit prevailed at the time, as Zhang writes: "those who were selected as model workers often were able to use the opportunity to enter the political stage, which helped to forge the common belief that ordinary jobs can offer valuable contributions to society and even the possibility of being transferred to a leadership position." In Mao's time, however, valuing workers was accompanied by a radical form of anti-intellectualism. Today, the challenge is one of valuing different forms of political merit without radical critiques of forms that fall outside those valued by the state (and without violence directed at people from "bad" class backgrounds).

The greatest resource for maintaining legitimacy, Zhang argues, is the "mass line," which stems from the revolutionary era:

The mass line, the Party term for a policy aimed at cultivating contacts with the common people, emphasized the idea of coming from the masses and going among the masses. It represents opposition to the idea that a minority or elites should be able to pursue top-down policies. Instead it argues that the understanding of truth is a process that is constantly being revised by collective practice and that close contact with the masses is necessary to reach a more realistic situation of the country's situation, which in turn is critical for formulating the correct party line and policies.... To put the concept of mass line into practice, it's necessary to "find the masses." This not only requires the cadres to go out into the masses, but also necessitates a certain level of organization on the part of grassroots society, in order to create connections between the grassroots, policymakers, and the executive branch, which helps policymakers become more responsive to grassroots society. A system of government that is highly responsive to the people is very likely to earn their support. 
Zhang's argument is thought provoking. The mass line put into practice is a way of securing widespread legitimacy for the political system without a system of competitive elections. Today, it is encouraging that up-and-coming public officials in China typically need to spend extended periods in impoverished rural regions to help to make the cadres more sensitive to the needs of the worst-off members of the community. ${ }^{7}$ But opportunities for self-organization at the grass-roots level are insufficient at the moment.

Cao's article discusses Daoist critiques of meritocracy. Confucians and Mohists defended different conceptions of political meritocracy in the pre-Qin period, but the Daoists argued against the entire system. Laozi, the originator of Daoist thought, bluntly put forward the idea of not valuing or employing the virtuous:

Not to value and employ men of superior ability is the way to keep the people from rivalry among themselves; not to prize articles which are difficult to procure is the way to keep them from becoming thieves; not to show them what is likely to excite their desires is the way to keep them minds from disorder.

The basic idea is that any sort of competitive society—including a society that encourages competition according to a conception of political meritwill make people, especially the "losers," envious and miserable, so it is best to discourage any form of competition and desire for a better life. Hence, "the sage, in the exercise of government ... constantly tries to keep people without knowledge and without desire, and where there are those who have knowledge, to keep them from presuming to act on it." The ruler should limit politics driven by competitive feelings and ambition, which means not employing the wise and the virtuous.

In the same vein, Zhuangzi discouraged the use of the wise and virtuous. He shares Laozi's view that "elevating the worthy" will lead to a competitive and chaotic society: "if you raise the men of talent to office, you will create disorder; making the people strive with one another for promotion; if you employ

7 During the Cultural Revolution, millions of educated urbanites had to spend extended periods in the countryside to be "educated" by farmers. It was a miserable experience for many intellectuals (especially because they had no indication of when they could return to the cities), but it did have the positive consequence that public officials in charge of the initial period of economic reform had experience in the countryside and a good feeling for the needs of the farmers (I thank Wang Hui for this insight). In more recent years, the cadres lost touch with the "masses" and were more likely to implement policies insensitive to their needs. 
men for their wisdom, the people will rob each other." Zhuangzi goes further by casting doubt on the whole idea of distinguishing between those with more and less worth. Everyone has limited talent and a biased perspective:

No one has covered or extended the whole range of truth ... there is a limit to our life, but to knowledge there is no limit. With what is limited to pursue after what is unlimited is a perilous thing; and when, knowing this, we still seek the increase of our knowledge, the peril cannot be averted.

Humans can only dwell in specific places, be present in a specific situation, and obtain limited knowledge, yet they often regard their own view as the whole truth and argue endlessly from and for their limited perspective: "So it is that we have the contentions between the Confucians and the Mohists, the one side affirming what the other denies and vice versa." And however brilliant a sage may be, he cannot avoid becoming entangled in social connections and political plots that lead to disaster: "Longfeng was beheaded; Bigan has his heart torn out; Chang Hong was ripped open; and Zixu was reduced to pulp. Worthy as these four men were, they did not escape dreadful deaths." So the solution is to abandon the whole idea of pursing wisdom: "in the age of perfect virtue, they attached no value to wisdom, nor employed men of ability."

The Lao-Zhuang tradition may seem extreme in its anti-intellectualism. But it reminds us of our necessarily limited perspectives and of the need to distrust those who arrogantly claim to know the whole truth and confidently assert their political effectiveness. The solution is not to abandon the idea that some perspectives are better than others - at the very least, even Zhuangzi would agree that those who are aware of their limitations are better than those who are not. Nor is the solution to abandon the political aim of selecting and promoting those with above-average talent and virtue. What must be done is to employ officials with diverse talents and different perspectives to help compensate for the necessary limitations of any one person. Cao shows that the Huang-Lao tradition drew on Daoist insights for political purposes:

Being a political ideology, Huang-Lao thought had to use the talented and the virtuous to implement and carry out, and therefore could not possibly unconditionally suspect and reject the talented and virtuous like the Lao-Zhuang tradition did, let alone consider them to be initiators of turmoil. On the contrary, why sages were needed, what kind of sages were needed, and how to make use of them were important elements of Huang-Lao political thought. 
In political practice, the monarch needs to recognize that he cannot do everything on his own and he needs to employ public officials with superior talents. Even the wisest sages have limited knowledge and perspectives and need assistance (and criticism): "since the ruler's wisdom and talents are not sufficient to spread his splendor across lands and seas, he is surrounded by high ministers who assist him." To allow public officials to flourish and make contributions, the monarch must practice inaction: "if the ruler is able to renounce his own wisdom, talent, and accomplishments, he will be able to bring fully into play his people's wisdom, talent, and accomplishments." Given necessarily limited knowledge and perspectives, the monarch should strive to employ different kinds of public officials with different backgrounds and different skills: diverse "types of men have opposite characters, however sages can still use them in a tolerant way.... If guarding just one corner means leaving out the rest of the world, and selecting one species means giving up all other beings, one is sure to achieve very little: the reach of one's administration will certainly be very narrow." In short, the monarch should be aware of his limitations and make comprehensive use of public officials with diverse backgrounds and talents.

In a political system without a monarch, the Huang-Lao school of thought might counsel against one-person rule, especially if the ruler is buttressed by a cult of personality that portrays him as all-wise and benevolent. In a system of collective leadership, diverse perspectives can inform the policy-making process at the very top. In a large country such as China, collective leadership at the top also needs to be supported by an extensive bureaucracy at different levels of government staffed with a wide range of public officials from diverse backgrounds with diverse talents. But even this kind of system would not fully assuage Daoist worries about the downside of political meritocracy: in the modern world, even a well-functioning political meritocracy that selects and promotes public officials with diverse talents and backgrounds needs to be supported by an ultracompetitive education system that aims to identify and educate those with above-average ability and talent, and the dominant competitive ethos of that society will lead to endless striving for success that causes misery for the "losers" and hence sows the seeds of social disorder. And these Daoist worries would be further exacerbated in a capitalist economic system that rewards companies that successfully invent new needs and desires for consumers who are never supposed to be satisfied with the status quo.

So what can be done to soften the deleterious societal effects of political meritocracy in the modern age? Perhaps the best way is to emphasize that being a professional public official is not the only way to lead a meaningful life. 
This means assigning more social (and material) value to "nonpolitical" ways of life that contribute to the social good, such as the lives of farmers, family caregivers, and manual laborers. It also means allowing for mechanisms that cast doubt on the meritocratic system, but without really threatening the entire system. Perhaps the most fascinating social development in contemporary China has been the rapid spread of a "culture of cuteness": a public affirmation of cute animals, robots, and emojis that inform everyday social interaction. The trend started in Japan in the $1970{ }^{8},{ }^{8}$ when Japan was largely ruled by meritocratically selected leaders selected in an ultracompetitive education system. It was led by teenage girls and eventually spread to other sectors of society. Over the past decade or so, the culture of cuteness has spread to China almost like wildfire. The streets of Chinese cities are crowded with ridiculously cute dogs and cats, and the use of cute emojis is almost mandatory for communication on social media, even in official settings, such as exchanges between university administrators. ${ }^{9}$ It is worth asking why the culture of cuteness has planted social roots so quickly and so deeply in China. One explanation is that it is helpful for meritocratic competition: according to one recent study, viewing cute images promotes careful behavior and narrows attentional focus, with potential benefits for learning and office work. ${ }^{10}$ But the deeper reason may be both disturbing and encouraging for defenders of political meritocracy. On the one hand, the culture of cuteness represents a kind of rebellion against the entire system: instead of affirming the value of boring and hard-working (largely male) bureaucrats who serve the public good, it affirms the value of playful and somewhat self-indulgent ways of life. On the other hand, the culture of cuteness reduces the desire to join the "race to the top," which helps to

$8 \quad$ Paul Ratner, “Why Do Japanese People Love Cuteness? Learn the Science of 'Kawaii', Big Think. http://bigthink.com/paul-ratner/why-do-the-japanese-love-cute-things/.

9 This is not meant to be a criticism. One of the problems with traditional email is that messages that rely on text often have difficulty in conveying emotions and hence could be easily misunderstood. But now we can add a smiley face or other such symbols of emotions to convey the feelings meant to accompany our messages, which reduces the risk of misunderstanding. On the other hand, the use of cuteness and emojis could also dampen critical thinking, feeding materialist urges and distracting the public from taking or expressing critical views of officials and the political system. The effect of emoji use and cuteness is yet to be fully explored.

10 Hiroshi Nittono et al., "The Power of Kawaii: Viewing Cute Images Promotes a Careful Behavior and Narrows Attentional Focus," Plos One, September 26, 2012. http://journals. plos.org/plosone/article?id=10.1371/journal.pone.0046362. I thank Julien Bell for sending this study. 
placate the "losers" in the political meritocracy and hence stabilizes the meritocratic system.11

To summarize: if the task is to improve and consolidate vertical democratic meritocracy, we can learn much not just from Confucians and liberal democrats but also from Maoists and Daoists. More specifically, both Maoist and Daoist ideas can help to promote the legitimacy of the system among those left out of official power hierarchies in political meritocracies that lack the safety valve of electoral competition for higher-level political posts. The Maoist mass line can help to provide avenues for grass-roots participation in politics and make elites more responsive to the needs of the masses. And Daoist-style skepticism about the desirability of the meritocratic system can help to legitimatize alternative avenues for socially valued ways of life, such as the "culture of cuteness," which give meaning to the lives of those shutout of the political hierarchies.

\section{Works Cited}

Bell, Daniel. The China Model: Political Meritocracy and the Limits of Democracy. Princeton: Princeton University Press, 2015.

Fukuyama, Francis. Political Order and Political Decay: From the Industrial Revolution to the Globalization of Democracy. New York: Farrar, Straus and Giroux, 2015.

Nittono, Hiroshi et al. "The Power of Kawaii: Viewing Cute Images Promotes a Careful Behavior and Narrows Attentional Focus." Plos One, September 26, 2012. http:// journals.plos.org/plosone/article?id=10.1371/journal.pone.0046362.

Ratner, Paul. "Why Do Japanese People Love Cuteness? Learn the Science of 'Kawaii'” Big Think. http://bigthink.com/paul-ratner/why-do-the-japanese-love-cute-things/. Wang Pei. "Debates on Political Meritocracy in China: A Historical Perspective." Philosophy and Public Issues 7, no. 1 (2017):53-71.

11 If the culture of cuteness is (at least partly) a reaction to an ultracompetitive meritocratic political system underpinned by an ultrameritocratic education system, one might expect the culture of cuteness not to have a substantial social impact in societies that are more easygoing and less competitive. This hypothesis is supported by the fact that the culture of cuteness has had little social impact in the world's happiest countries, such as Norway and Denmark. Though it does seem to be taking hold in the US via increasing development of emojis, which may speak less about a reaction to competition and more about a feeling of alienation, political helplessness or economic anomie. 